\title{
Multi-performance optimisation framework for the selection of structural alternatives based on sustainable qualities
}

\author{
S. Eleftheriadis \& D. Mumovic \\ UCL Institute for Environmental Design and Engineering, University College London, United Kingdom
}

P. Duffour

Department of Civil, Environmental \& Geomatic Engineering, University College London, United Kingdom

P. Greening

Department of Civil Engineering, Coventry University, United Kingdom

\begin{abstract}
In recent years, the increasing demand for innovative sustainable policies in building engineering has shifted the decision rationale from traditional performance-based systems towards systems augmented by life-cycle sustainability notions. This paper investigates a novel optimisation framework, which supports the selection of buildings' structural alternatives at concept stage by applying multiple performance, sustainable requirements. The established model explores ways to effectively compute and process expert knowledge across different stakeholders groups into a consolidated decision-making platform supported by Lean Theory. A systematic procedure based on the Quality Function Deployment is utilised to successfully translate 16 sustainability requirements into 27 corresponding engineering design requirements. The theoretical and mathematical principles of Analytic Network Process are applied on a pilot study to build general decision clusters, identify feedback links amongst the various engineering criteria and determine their inner dependences.
\end{abstract}

\section{INTRODUCTION}

\subsection{Background}

(Russell-Smith et al., 2015) have recognised the need for decision-making systems that systematically reduce the environmental impacts in building design, construction and operation by augmenting the overall sustainability of building materials and systems. The optimisation and selection of structural systems/materials and the increased sustainability knowledge of the decision-makers are amongst the important parameters that could improve the overall sustainability of a building's system (Ljungberg, 2007).

Different decision-makers often give different importance levels to the various sustainable criteria based on their relative experiences and based on their sensitivity to sustainability (Singhaputtangkul et al., 2014). According to (Gervasio \& da Silva 2012; Singhaputtangkul et al. 2014) the development of sustainable building systems involves a multidimensional, often contradicting set of performance criteria spanning across societal, economic and environmental dimensions. Furthermore, the decisionmaking processes are considered appropriate for the selection of design solutions once they satisfy conflicting sustainability requirements. The selection of the appropriate method requires understanding of the complexities involved in the decision criteria, the process requirements and the availability of information and knowledge about the problem space (Huang et al., 2011). (Ullman, 2001) has classified the required information for decision-making in de- sign process under three fundamental, interlinked categories consisting of data, models and knowledge coupled with relationships, behaviours and the associated judgment component. The main drivers of the sustainability insights in the construction industry's decision makers on the other hand are: 1) Technology advancements and 2) People's perception of change (Zhang et al., 2014).

\subsection{Sustainability Requirements Consolidation}

Sustainable concepts in construction systems require integration with Energy, Materials, Waste, and Pollution related attributes (Ahuja, 2012). Several authors have specified a diverse set of sustainability related criteria during the decision-making exercises. (Baharetha et al., 2012) have proposed a set of environmental, technological, resource-using and socioeconomic categories that could offer a unified metric for material selection. A comprehensive survey of previous literature was conducted on this topic by the authors (Eleftheriadis et al. 2016). The outcomes from this analysis have been used in this paper to establish sustainability requirements (SR) associated with the material and structural systems' selection. The extensive list of SR is summarised in Table 1 and grouped in four categories comprising of Environmental, Economic, Social and Technical attributes. Each of the 16 SR needs to be maximised or minimised. In real-life projects it becomes evident that the different requirements correspond to different individual weights depending on the stakeholders' preferences and projects' needs. 
Table 1. Sustainable requirements for the selection of structural systems and materials

\begin{tabular}{lllll}
\hline Criterion & Category & Group & \multicolumn{2}{l}{ Occurrence } \\
\hline Life-cycle Impacts & Environmental & SR1.1 & $16 / 16$ & $(\downarrow)$ \\
Recycling Potential & Environmental & SR1.2 & $7 / 16$ & $(\uparrow)$ \\
Waste \& Pollution & Environmental & SR1.3 & $10 / 16$ & $(\downarrow)$ \\
Resource-use & Environmental & SR1.4 & $12 / 16$ & $(\downarrow)$ \\
Material Costs & Economic & SR2.1 & $15 / 16$ & $(\downarrow)$ \\
Construction Costs & Economic & SR2.2 & $15 / 16$ & $(\downarrow)$ \\
Operation/Maintenance & Economic & SR2.3 & $14 / 16$ & $(\downarrow)$ \\
Disposal Costs & Economic & SR2.4 & $11 / 16$ & $(\downarrow)$ \\
Health \& Safety & Social & SR3.1 & $8 / 16$ & $(\uparrow)$ \\
Aesthetics & Social & SR3.2 & $8 / 16$ & $(\uparrow)$ \\
Noise Disturbance & Social & SR3.3 & $6 / 16$ & $(\downarrow)$ \\
Impacts on Users & Social & SR3.4 & $7 / 16$ & $(\downarrow)$ \\
Buildability & Technical & SR4.1 & $6 / 16$ & $(\uparrow)$ \\
Construction Time & Technical & SR4.2 & $5 / 16$ & $(\downarrow)$ \\
Availability (Materials) & Technical & SR4.3 & $4 / 16$ & $(\uparrow)$ \\
Durability & Technical & SR4.4 & $12 / 16$ & $(\uparrow)$ \\
\hline
\end{tabular}

\subsection{Paper Organisation}

The optimisation framework presented herein is part of a larger research project, which is currently under development and aims to support holistic sustainable decisions in the structural engineering field. The outcomes obtained in this study provide useful, practical and intellectual connections with the next phases of this project. Having reviewed the current developments in sustainability decision models, this paper presents the broader capabilities of a novel optimisation framework, whilst investigating a systematic way to translate SR into structural engineering requirements (ER). At this phase of the project, a pilot study, organised in focus groups was designed to collect information about the possible implications of life-cycle sustainability considerations in structural engineering practice and establish a network of ER that will be allocated in the rest of the project using a comprehensive computational model. The objectives of this study are threefold:

1. To introduce the conceptual foundations of the general framework, utilising Lean Theory measures - Section 2

2. To establish the optimisation mechanism and its corresponding phases associated with the Quality Function Deployment (QFD), Analytical Network Process (ANP) and Building Information Modelling (BIM) components - Section 3

3. To conduct pilot workshops with structural engineers and review the findings from the translation of SR to ER-Section 4

\section{DECISION MODEL SYNTHESIS}

\subsection{Conceptual Notions}

The main notion behind the current paper is that structural systems cannot be examined and optimised in isolation. Instead, they should be considered as an integrated building component in constant interaction with the rest of the buildings' systems (architecture, construction, services, energy, environment). To achieve this integration and to address the limitations associated with the selection of structural systems, decision procedures are required to assess and conceptualise these complexities and interrelations (Salem et al., 2006).

In addition, the implementation of sustainable principles in construction projects complicates this situation further: a clear understanding of the decision-making processes and stakeholders' preferences are needed. (Rydin et al., 2007). In this manner, rather than proposing a "correct - global" decision the goal becomes to describe and articulate a decision that best suits the decision makers' current needs and their understanding of the problem. Considering this, by collectively analysing the overall sustainability performance objectives and their corresponding significance rankings, costly redesigns could be reduced, whilst trade-offs amongst the technicalengineering performance qualities could be identified.

\subsection{Lean Theory}

The concepts and principles of lean are focusing on how to make a production system leaner by eliminating waste and maximising its value stream through continuous improvements in process and product design (Ahuja, 2012). The concept of continuous improvement in design helps obtain customers' satisfaction, which is the ultimate objective in any decision-making problem (Pangsri, 2014). In the construction industry, in particular lean concepts have the potential to promote innovative changes (Ogunbiyi et al., 2013).

In addition, (Huovila \& Koskela 1998; Ahuja 2012) have insisted that lean philosophy offers the conceptual underpinning for sustainable development in construction (improve a system's economic value but also to offer environmental and social benefits). (Ogunbiyi et al., 2013) have noted that stakeholders' commitment and knowledge are the main parameters that influence the implementation of lean principles within the construction systems' sustainability. (Bjornfot, 2008) proposed a theoretical model of lean construction approach associated with the design of structural systems, considering four dimensions: 1) Product standardisation, 2) Process standardisation, 3) Workload reduction and 4) Organisation strength.

The lean 3P concept is part of the Lean Theory, focusing on Production, Preparation and Process. Lean $3 \mathrm{P}$ promotes an early collaboration of the main stakeholders during the design process (Coletta, 2012). The underlying principle of $3 \mathrm{P}$ involves understanding of "customers' needs" and developing alternatives that offer a breakthrough through collective design efforts. According to (Pangsri, 2014) the 
main advantages of 3P involve: 1) Cross-functional team approach, 2) Rapid testing of ideas, and 3) Embedding lean principles into product and process design. The concept of lean $3 \mathrm{P}$ has been interpreted in this study to provide an effective decision framework in structural engineering.

\subsection{Proposed Lean Decision Hierarchy}

The model we propose allows structural engineers and the rest of the stakeholders to systematically assess decision procedures in buildings' structural systems following a 3-tiered classification procedure:

1. Characterisation: the preliminary interactions between the various stakeholders and experts (technical and non-technical),

2. Development: the processes associated with the articulation of the problem development and design alternatives,

3. Appraisal: stakeholders' interactions related to the final assessment and decision-making.

In order to achieve a more comprehensive overview of the proposed Characterisation, Development and Appraisal (CDA) decision hierarchy, 9 subsequent levels are identified in Table 2.

Table 2. Lean decision hierarchy levels

\begin{tabular}{ll}
\hline Level & Activity \\
\hline L1 & $\begin{array}{l}\text { Specify conceptual mechanisms for the decision mod- } \\
\text { el and prepare project strategy }\end{array}$ \\
A2 & $\begin{array}{l}\text { Assemble team and liaise with other stakeholders us- } \\
\text { ing a shared communication platform }\end{array}$ \\
L3 & $\begin{array}{l}\text { Establish project sustainability performance objectives } \\
\text { considering costs, environmental impacts, etc. }\end{array}$ \\
L4 & $\begin{array}{l}\text { Transform project criteria into engineering design re- } \\
\text { quirements }\end{array}$ \\
L5 & $\begin{array}{l}\text { Integrate computational tools and specify relationships } \\
\text { R6 }\end{array}$ \\
R7 & $\begin{array}{l}\text { probresent objectives and constraints of the decision } \\
\text { Enable data acquisition for a discrete set of structural }\end{array}$ \\
systems' alternatives & $\begin{array}{l}\text { Allow decision makers to rank design alternatives } \\
\text { based on projects' performance qualities }\end{array}$ \\
L9 & $\begin{array}{l}\text { Compute and identify the most preferred structural } \\
\text { system that qualifies for further analysis }\end{array}$ \\
\hline
\end{tabular}

\section{RESEARCH METHODOLOGY}

\subsection{Optimisation Framework}

In the current study the filtering assemblies have been applied in the field of buildings' structural systems. The aim of the aforementioned synergistic decision scheme is to facilitate group decision-making processes as well as to enhance the performance qualities of structural system alternatives by finding optimum solutions that meet both the sustainability and the engineering requirements. The proposed op- timisation framework's representation of the 9 CDA decision hierarchies is shown in Figure. 1.

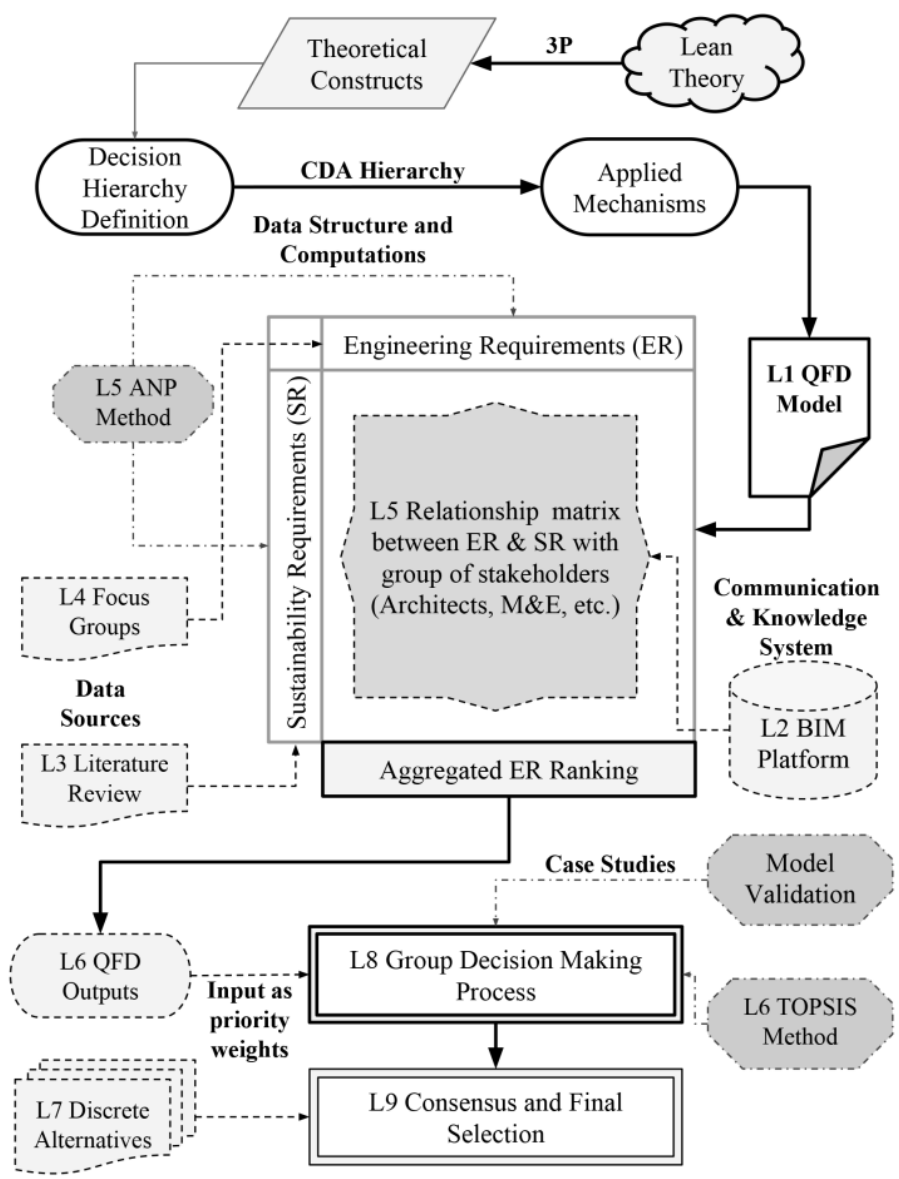

Figure 1. Phases of the proposed framework

The application has been structured around 2 main components: 1) QFD model and 2) Multi-criteria Decision-Making (MCDM) model. Firstly, QFDbased matrices have been selected for this study to help identify and prioritise engineering methods that systematically address sustainable project requirements. The priorities specified in the QFD model are thereafter, utilised as input data into the MCDM model, where a discrete set of structural systems and materials are mapped against them in order to identify the preferred design alternative based on stakeholders' preferences. In this paper the mechanisms associated with levels L1 to L5 of the framework are further explored over the next sections. BIM has been used for the collection of QFD-related data from the stakeholders, whilst ANP is used for the prioritisation and organisation of the QFD components:

1. SR weightings (from all the stakeholders),

2. ER correlation (from the structural engineers)

3. ER-SR relationship matrix (from all the stakeholders).

The relationship matrix of ER and SR will not be covered on this paper. Structural engineering practitioners were invited to develop the list of ER based on the specific SR identified in the literature. 


\subsection{Sustainable QFD Application}

QFD is a cross-functional planning tool that ensures customers' needs are effectively translated into engineering characteristics. In the sustainable QFD model of this study, the customers' needs are denoted from the network of 16 SR identified in Table 1 containing both quantitative and qualitative attributes. House of Quality (HoQ) is the matrix used to translate SR into ER and identify priorities of ER often based on a point scoring scale (Buyukozkan et al., 2004). A series of focus groups with structural engineers are organised to translate the selected SR into ER. The main elements of the proposed HoQ with the relevant computation procedures are shown in Figure 2.

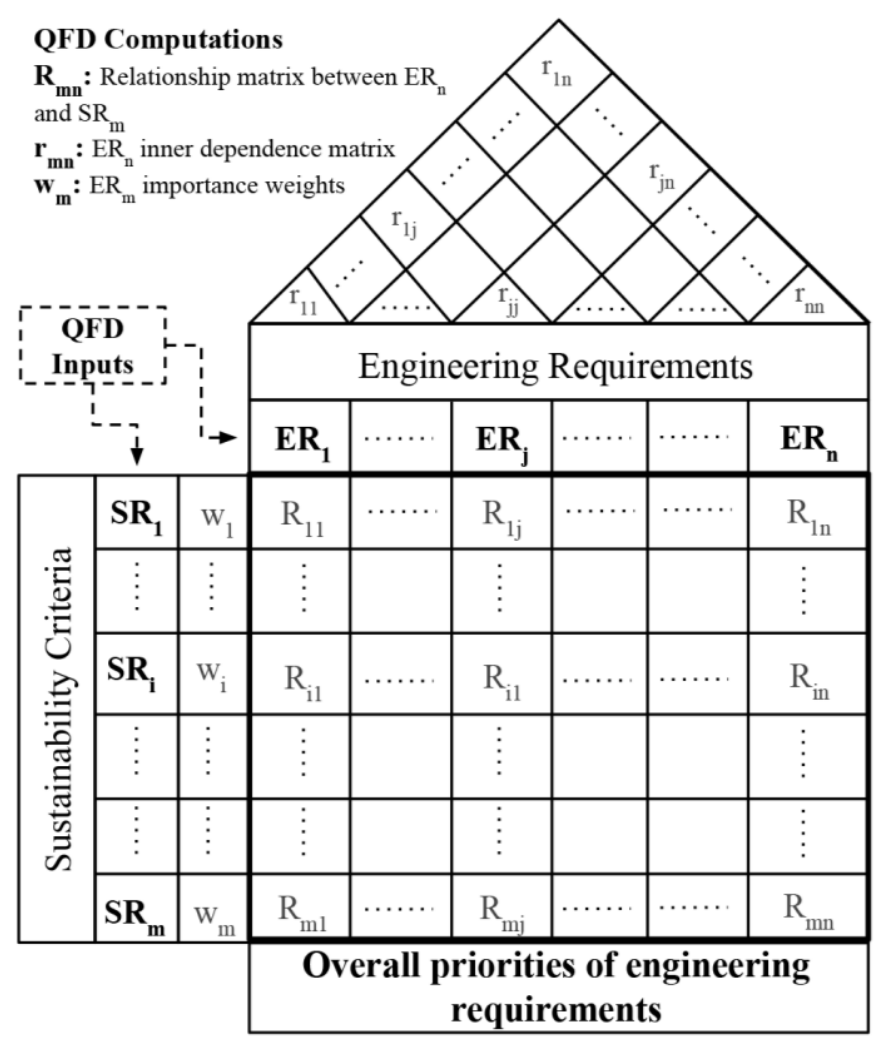

Figure 2. QFD House of Quality (HoQ)

\subsection{BIM Module}

(Bank et al., 2010) have discussed the possibility of implementing the information contained within BIM to assist decision-makers in improving the sustainability performance of their buildings. In addition, (Antucheviciene et al., 2015) have recognised the possibility of enhancing the current BIM-based applications with decision support systems that assist the existing multi-criteria problem-solvers. In this study BIM is utilised as the shared knowledge platform where the different stakeholders specify their preferences of project systems based on shared decision criteria. A BIM-based module is proposed to collect perceived importance weightings in real time from a diverse group of stakeholders including ar- chitects, structural engineers, contractors, M\&E engineers, clients, project managers and quantity surveyors. The preferences are recorded and processed in the QFD model as shown in the previous section.

\subsection{ANP Computations}

SR and ER are organised under multi-level networks based on the ANP method. ANP uses ratio scale measurements to capture the interactions between the nodes and the clusters of a network. The main advantage of this approach is that allows the computation of aggregated ER priorities in the QFD model. In this way, an ER node that influences other nodes of the network is more significant than one with little or no impact on other nodes. The ratio scales are derived from the principal Eigen vectors and the consistency index from the principal Eigen value (Buyukozkan et al., 2004). For the SR 4 clusters with 16 nodes have been assumed (Section 1.2). The nodes and clusters of ER are obtained from the focus group workshops presented in Section 4. Fuzzy Set Theory and particularly triangular fuzzy membership with linguistic weighting mechanisms is integrated into the ANP to address the ambiguity and the imprecision of human perception that is related to qualitative ranking procedures.

\section{PILOT STUDY}

\subsection{Focus Groups}

Instead of conducting one-to-one interviews, focus groups have been selected at this phase of the project to study structural engineers' perception of sustainable decision-making. Three advantages from performing interactive focus groups sessions have been recognised: 1) They allowed a larger sample to be studied, 2) They enabled knowledge exchange between the participants and 3) They helped identify patterns amongst organisations. Nine hourly focus groups were organised in early 2016, consisting of five to nine engineers ranging from Graduate Engineers to Partners. Sixty structural engineers from a UK-based consultancy were selected for this phase of the study. The focus groups comprised two parts and were overseen by two moderators (dual moderator focus groups). In the first part of each session, the aim was to establish an understanding of the elements that currently drive sustainable practices in structural engineering. In the second part of the focus groups, all participants were asked to identify structural engineering methods drawn from their experiences in order to address SR. The role of the moderators in both parts was to initiate and support the round-table discussions using assistive questions (5-8 interactive questions). Participants were free to talk to the rest of the group members. The focus groups reached to a saturation point after group 
number 6 , when no further methods were added to the established ER list. After each session, the audio files were post-processed and general findings were recorded and summarised.

\subsection{Current Practice}

The authors have attempted to consolidate the observations from the nine sessions regarding the current decision rationale in structural engineering:

1. Engineers tend to feel disengaged when they do not have the opportunity to influence directly the problem-solving and decision processes.

2. Engineers' sustainability experience and understanding significantly affect the teams' perception of optimised sustainable alternatives.

3. Systematic mechanisms that facilitate engineers' expert opinion into decision procedures are rarely implemented in practice.

4. Real-life engineering problems often involve local knowledge (experiences), which are often underutilised.

Overall, all groups reported that the combination of collective intelligence, quantitative analysis and effective policies is considered an important approach that could improve the overall quality of the existing decision models in practical real-life structural engineering projects.

\subsection{ER Network Model}

The organisation of ER network follows the concept of structural systems' life-cycle. Five clusters related to Design (ER1), Manufacturing (ER2), Construction (ER3), Operation (ER4) and End-of-Life (ER5) are proposed. The resulting list of ER consisting of twenty-seven comprehensive criteria is summarised in Table 3. Two types of relationships are recognised within the proposed ER network: 1) Feedback loops between the nodes of the five clusters and 2) Inner dependencies amongst the nodes of each cluster. Figure 3 shows the representation of the ANP network as prepared in Super Decisions software for the ER.

After establishing and calibrating the model the next step in the QFD process includes data collection by surveying the sample of engineers in the focus groups and quantifying perceived importance rankings and interrelationships for all the ER (pairwise comparisons). The questions are formulated in terms of dominance or influence. For example: Given a parent node, which of two nodes being compared with respect to it has greater influence (i.e. is more dominant) with respect to that parent node? Or which is influenced more with respect to the parent node? The on-line questionnaire with the detailed ER pairwise comparisons has been distributed to the engineers-participants. The numerical/statistical outcomes are currently reviewed and processed.
Table 3. Proposed ER classification

\begin{tabular}{lll}
\hline Cluster & Requirements & \\
\hline ER1 & ER1.1 Structural Performance & $(\uparrow)$ \\
& ER1.2 Lean Design Measures & $(\uparrow)$ \\
& ER1.3 Loadings Reconciliation (climate change) & $(\uparrow)$ \\
& ER1.4 Design Standardisation & $(\uparrow)$ \\
& ER1.5 Design Complexity & $(\downarrow)$ \\
& ER1.6 Structural Elements Optimisation & $(\uparrow)$ \\
& ER1.7 BIM Modelling and Visualisation & $(\uparrow)$ \\
ER2 & ER2.1 Embodied Emissions & $(\uparrow)$ \\
& ER2.2 Re-use Components \& Materials & $(\uparrow)$ \\
& ER2.3 Recycled Content Materials & $(\uparrow)$ \\
& ER2.4 Responsibly Sourced Materials & $(\uparrow)$ \\
& ER2.5 Locally Sourced Materials & $(\uparrow)$ \\
& ER2.6 Alternative Materials & $(\uparrow)$ \\
ER2.7 High Strength/ Grade Materials & $(\uparrow)$ \\
ER3.1 Prefabrication and Off-site Construction & $(\uparrow)$ \\
& ER3.2 Effective Construction Sequence & $(\uparrow)$ \\
& ER3.3 Construction Complexity & $(\downarrow)$ \\
& ER3.4 Building Systems Synergies & $(\uparrow)$ \\
ER3.5 Exposed Structures/Finishes & $(\uparrow)$ \\
ER4 & ER4.1 Energy Use (heat sinks, radiant floors) & $(\downarrow)$ \\
& ER4.2 Harmful Adhesives, Paints, Coatings & $(\downarrow)$ \\
& ER4.3 Thermal/Cold Bridging & $(\downarrow)$ \\
& ER4.4 Fire Resistance & $(\uparrow)$ \\
& ER4.5 Vibrations & $(\downarrow)$ \\
& ER5.3 Design for Future Flexibility & $(\uparrow)$ \\
& & $(\uparrow)$ \\
\hline
\end{tabular}

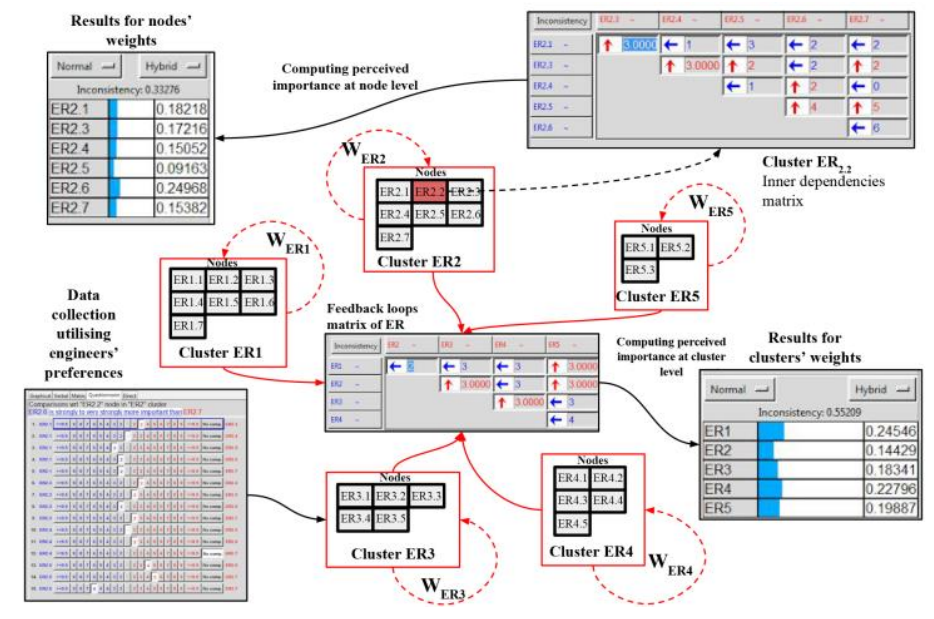

Figure 3. Proposed matrix of ER network, clusters and nodes

\section{CONCLUSION}

The current challenges of sustainable decision practices in real-world engineering applications are addressed in this paper. The study has drawn concepts from literature of Lean Theory to establish a novel decision hierarchy within structural engineering by interpreting the principles of Lean 3P. In addition, an optimisation framework that utilises group MCDM and QFD is presented in this paper, to offer a systematic approach in identifying structural alter- 
natives based on both sustainability and engineering requirements. The mechanisms explored in this paper, cover the first phases of a larger research project. Sustainable requirements associated with the selection of structural systems and materials have been recognised from an extensive review of the literature. Furthermore, focus groups from a UK-based engineering practice were utilised to transform the selected sustainability requirements into engineering requirements. Drawing from engineers' previous experiences the focus groups have offered not only valuable insights about the current sustainable decision rationale in structural engineering but also a comprehensive list of twenty-seven structural engineering methods, which were organised in five clusters. A computational model of the network's structure with the corresponding relationships is also presented. Detailed data collection and validation of the model is currently under development.

\section{REFERENCES}

Ahuja, R 2012, 'Sustainable Construction: Is Lean Green?', ICSDEC 2012: Developing the Frontier of Sustainable Design, Engineering, and Construction, American Society of Civil Engineers, Fort Worth, Texas, United States.

Antucheviciene, J, Kala, Z, Marzouk, M \& Vaidogas, ER 2015, 'Solving Civil Engineering Problems by Means of Fuzzy and Stochastic MCDM Methods: Current State and Future Research', Mathematical Problems in Engineering, pp. 116.

Baharetha, SM, Al-Hammad, AA \& Alshuwaikhat, HM 2012, 'Towards a Unified Set of Sustainable Building Materials Criteria', International Conference on Sustainable Design, Engineering, and Construction, Fort Worth, Texas, United States.

Bank, LC, McCarthy, M, Thompson, BP \& Menassa, CC 2010, 'Integrating BIM with System Dynamics as a DecisionMaking Framework for Sustainable Building Design and Operation', First International Conference on Sustainable Urbanization, Hong Kong, China.

Bjornfot, A 2008, 'An engineering perspective on lean construction theory', IGLC 16 Proceedings : 16th Annual Conference of the International Group for Lean Construction, University of Salford, U.K, Manchester, UK.

Buyukozkan, G, Ertay, T, Kahraman, C \& Ruan, D 2004, 'Determining the Importance Weights for the Design Requirements in the House of Quality Using the Fuzzy Analytic Network Approach', International Journal of Intelligent Systems, vol 19, pp. 443-461.

Coletta, AR 2012, The Lean 3P Advantage: A Practitioner's Guide to the Production, CRC Press, Boca Raton, Florida.

Eleftheriadis, S, Duffour, P, Mumovic, D \& Greening, P 2016, 'Conceptual challenges in material selection of buildings' structures: The prospects of sustainable decision quality frameworks - Manuscript in preparation'.

Gervasio, H \& da Silva, LS 2012, 'A probabilistic decisionmaking approach for the sustainable assessment of infrastructures', Expert Systems with Applications, vol 39, pp. 7121-7131.

Huang, IB, Keisler, J \& Linkov, I 2011, 'Multi-criteria decision analysis in environmental sciences: Ten years of applications and trends', Science of the Total Environment, vol 409, no. 19, pp. 3578-3594.

Huovila, P \& Koskela, L 1998, 'Contribution of the Principles of Lean Construction to Meet the Challenges of Sustainable Development', Proceedings IGLC-6, Guaruja, Brazil.

Ljungberg, LY 2007, 'Materials selection and design for development of sustainable products', Materials \& Design, vol 28, pp. 466-479.

Ogunbiyi, OE, Oladapo, AA \& Goulding, JS 2013, 'A review of lean concept and its application to sustainable construction in the UK', International Journal of Sustainable Construction Engineering \& Technology, vol 4, no. 2 .

Pangsri, P 2014, 'A Decision Framework to Select Alternative based on Lean manufacturing Concepts in Design Processes', Journal of Industrial and Intelligent Information, vol 2, no. 1, pp. 1-5.

Russell-Smith, SV, Lepech, MD, Fruchter, R \& Meyer, YB 2015, 'Sustainable target value design: integrating life cycle assessment and target value design to improve building energy and environmental performance', Journal of Cleaner Production, vol 88, pp. 43-51.

Rydin, Y, Amjad, U \& Whitaker, M 2007, 'Environmentally sustainable construction: Knowledge and learning in London planning departments', Planning Theory and Practice, vol 8, no. 3, pp. 363-380.

Salem, O, Solomon, J, Genaidy, A \& Minkarah, I 2006, 'Lean Construction: From Theory to Implementation', Journal of Management in Engineering, vol 22, no. 4, pp. 168-175.

Singhaputtangkul, N, Low, SP, Teo, AL \& Hwang, B-G 2014, 'Criteria for Architects and Engineers to Achieve Sustainability and Buildability in Building Envelope Designs', Journal of Management in Engineering, vol 30, pp. 236-245.

Ullman, DG 2001, 'Robust decision-making for engineering design', Journal of Engineering Design, vol 12, no. 1, pp. 313.

Zhang, X, Wu, Y, Shen, L \& Skitmore, M 2014, 'A prototype system dynamic model for assessing the sustainability of construction projects', International Journal of Project Management, vol 32, pp. 66-76.

\section{ACKNOWLEDGEMENTS}

This research has been made possible through funding provided by the Engineering and Physical Sciences Research Council (EPSRC) and from Price \& Myers LLP, and this is gratefully acknowledged here. The authors would also like to express a sincere thank you to the sixty structural engineers from Price \& Myers who so graciously agreed to participate in this study. 